\title{
Study of the impacts of upstream natural gas market reform in China on infrastructure deployment and social welfare using an SVM-based rolling horizon stochastic game analysis
}

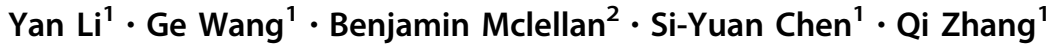

Received: 28 November 2017 / Published online: 27 June 2018

(c) The Author(s) 2018

\begin{abstract}
Natural gas is expected to play a much more important role in China in future decades, and market reform is crucial for its rapid market penetration. At present, the main gas fields, pipelines and liquefied natural gas (LNG) infrastructure are mainly monopolized by large state-owned companies, and one of the important market reform policies is to open up LNG import rights to smaller private companies and traders. Therefore, in the present study, a game theoretical model is proposed to analyze and compare the impacts of different market structures on infrastructure deployment and social welfare. Moreover, a support vector machine-based rolling horizon stochastic method is adopted in the model to simulate real LNG price fluctuations. Four market reform scenarios are proposed considering different policies such as business separation, third-party access (TPA) and their combinations. The results indicate that, with third-party access (TPA) entrance into the LNG market, the construction of LNG infrastructure will be promoted and more gas will be provided at lower prices, and thus the total social welfare will be improved greatly.
\end{abstract}

Keywords LNG market reform · Market structure - Third-party access · Rolling horizon stochastic method . Game theory

\section{Abbreviations}

DP Domestic gas field producer

LI Original LNG importer

LT Subsequent LNG trader

\section{Indices}

$t$ The whole planning period (year, 2015-2022)

$r$ Roll (each roll including 3 years), the decision period updated every year

Edited by Xiu-Qin Zhu

Ge Wang

gewang_cupb@outlook.com

1 Academy of Chinese Energy Strategy, China University of Petroleum at Beijing, Beijing, China

2 Graduate School of Energy Science, Kyoto University, Kyoto, Japan $s \quad$ Scenario, including 4 scenarios, namely horizontal integration, single policy I (business separation), single policy II (TPA) and combined policies (business separation \& TPA)

$\bar{r} \quad$ Number of years in each roll $(\bar{r}=3)$

\section{Parameters (SVM), (Game)}

RLP Real long-term LNG prices (RMB), obtained year by year

$d \quad$ Discount rate

$b_{1}, b_{2} \quad$ Coefficients of demand

PC Unit production cost of domestic gas field, RMB

GC Unit regasification cost of LNG terminal, RMB

LP Stochastic long-term LNG prices, RMB

RT Unit cost of renting LNG terminal, RMB

RC Unit cost of LNG terminal construction, RMB

$\mathrm{PR}_{\mathrm{s}} \quad$ Probability of scenarios

FC First-stage cost

SC Second-stage cost

$\overline{\mathrm{Q}} \quad$ Domestic production capacity (billion cubic meter)

$\overline{\mathrm{C}} \quad$ Infrastructure construction capacity (billion cubic meter)

$\overline{\mathrm{R}} \quad$ Regasification capacity (billion cubic meter) 
SP Life span of LNG terminal

$\begin{array}{ll}\text { Variables } & \\ q_{1} & \begin{array}{l}\text { Production of domestic gas field (billion cubic } \\ \text { meter per year) }\end{array} \\ q_{2} & \begin{array}{l}\text { Production of LNG importer LI (billion cubic } \\ \text { meter per year) }\end{array} \\ q_{3} & \begin{array}{l}\text { Production of LNG importer LT (billion cubic } \\ \text { meter per year) }\end{array} \\ c & \begin{array}{l}\text { LNG terminal construction volume (billion } \\ \text { cubic meter) } \\ \text { Lagrange multiplier }\end{array}\end{array}$

\section{Introduction}

The Chinese government plans to double the share of natural gas in total primary energy consumption, from the current $5 \%$ to $10 \%$ by 2020 . Considering the limited domestic reserves and production, this implies that the country will have to rely more on imported liquefied natural gas (LNG) and pipeline gas imports. One of the most serious problems hindering natural gas's market penetration now in China is the inefficiency caused by monopoly, which suggests an urgent need to conduct market reform. However, at present the Chinese gas industry is characterized by an oligopolistic structure dominated by three large state-owned companies (China National Petroleum Corporation (CNPC), China Petrochemical Corporation (SINOPEC) and China National Offshore Oil Corporation (CNOOC)). These are not only natural gas producers and LNG importers, but also the owners and operators of pipelines and storage facilities. This integrated operation mode leads to very limited competition existing in the industry chain, and entry barriers are set accordingly with a high capital and technology requirement. Therefore, one of the most promising market liberalization methods is to permit third-party access (TPA) to LNG import facilities. When LNG import rights and facilities are open to third parties and more LNG is imported by private companies using a spot price, the domestic price is expected to become more closely linked with international markets. In particular, it is expected that it will facilitate a downward pressure on prices. Therefore, social welfare is expected to be increased, especially when the spot LNG price is much lower than the domestic production and long-term contract prices.

Many studies have shown that marketization of the whole natural gas industry chain would generate higher production and social welfare. Market competition could eliminate the cost caused by imperfect information (Devine et al. 2016; Paltsev and Zhang 2015). Tsygankova (2012) studied the introduction of market competition in the Russian natural gas market and found that although market competition would reduce the profit of monopolists, the total welfare of the whole industry is improved. On the other hand, there are also some studies to demonstrate that competition in the natural gas market cannot always work efficiently due to different market conditions. Gordon et al. (2003) concluded that market competition can neither enlarge the economy of scale, nor improve social welfare. Meanwhile, the change in market structure could lead to violent fluctuations on both demand and supply sides (Arano and Blair 2008; Gordon et al. 2003). China's natural gas market is still under monopoly with entrance barriers. Due to the tremendous market differences between China's market and foreign countries, the existing market models cannot be applied to China directly. Therefore, it is significant to study the potential market reforms for China's natural gas industry by using an independently developed model.

The previous models applied to natural gas market analysis are mainly based on game theory. De Wolf and Smeers (1997) used a Stackelberg-Nash-Cournot model to describe the equilibrium of the European natural gas market. Berton and Zaccour (2006) established and compared Cournot and Stackelberg game models of an asymmetric duopoly. Feijoo et al. (2016) developed the North America Natural Gas Model (NANGAM) to ascertain the impacts of energy reforms and cross-border trade. Egging et al. (2010) established a world gas model (WGM) to forecast the price and trading volume of LNG under different policy conditions, and Gabriel et al. (2012) analyzed the possibility and effects of cartelization in gas markets by using the model. GASMOD (Egging et al. 2008) and GASTALE (Lise et al. 2008) also address market power aspects explicitly via the complementarity format, but their coverage is only over Europe. However, these existing game theoretical models have not adequately reflected reality because uncertainty factors were not considered. Therefore, some studies have introduced stochastic factors into their natural gas models. Market participants make decisions by considering the contingency of natural gas demand (U-tapao et al. 2016; Zeng and Li 2016; Zhuang and Gabriel 2008). Panapakidis and Dagoumas (2017) forecast demand for natural gas based on a combination method of wavelet transform and an adaptive neuro-fuzzy inference system (ANFIS). Behrooz et al. (2017) used an unscented transform to characterize the demand uncertainty in dynamic planning models of natural gas network. Apart from demand, other factors such as LNG prices also exhibit high volatilities and randomness (Gong et al. 2016; van Goor and Scholtens 2014; Trotter et al. 2016). All of these previous studies were conducted based on the assumption of perfect predictions 
for the stochastic factors' probability distributions. However, a more realistic way is to estimate the stochastic factors based on relevant practical information rather than assumptions of probability distributions. As for factor estimation, it is always much more difficult to get complete information of the whole decision horizon rather than only two or three steps ahead. Therefore, some academics introduced the rolling horizon method into the stochastic process of the natural gas game model (Devine et al. 2016; Guigues et al. 2014). In the traditional approach, the decision for the whole time horizon is made in the first period with the assumption of perfect information for the LNG price probability distribution. However, in the proposed rolling horizon approach, the price information is practically imperfect with information available only two to three periods ahead. Moreover, the rolling horizon approach allows a two-level endogenous learning process and roll-by-roll update mechanism for game theory decisions. Devine et al. (2016) demonstrated that the rolling horizon stochastic approach can tackle the uncertainties more flexibly and accurately compared with traditional approaches.

In the present study, a game analysis model was developed to calculate the benefit of the LNG import market reform in China. Compared with existing studies on market structure (Lorenczik and Panke 2016), multi-stage stochastic factors such as LNG import price in the natural gas upstream market are considered, and an integrated stochastic approach is adopted to conduct dynamic planning with an endogenous probability distribution. Therefore, in the model, (1) the SVM method is used to forecast the LNG price as a stochastic factor to handle its uncertainties; (2) the rolling horizon method provides a dynamic planning framework based on the probability distribution obtained from the SVM forecast result, and roll-by-roll information update and endogenous learning; (3) a game theoretical method is applied to generate the final equilibrium decision of planning, maximizing individual profit of each market participant under the rolling horizon framework, and thus the decisions are also updated and adjusted roll by roll.

The game relationships among the state oil companies (SOCs) and private companies are focused and analyzed. Twolevel market equilibria are generated. The first level is in the LNG receiving capacity, in which the private company rents the surplus capacity from the capacity owners at a marketclearing price. The rent price and equilibrium rent capacity are codecided by both players with each pursuing their individual maximum profit. The second level is the equilibrium of all the natural gas suppliers and consumers. Here, the on-land natural gas producer is also in charge of pipeline imports and faced with a composite cost including extraction cost, transportation cost and long-term pipeline gas import cost. At the demand side, the market power of consumers is expressed by the demand function. The supply-demand balance is achieved by game equilibria among market participants with each pursuing their individual maximum profit.

The paper is structured as follows: An overview of the model framework and details of each method are introduced in Sect 2; an analysis of Chinese natural gas market reforms is performed in Sect. 3, followed by conclusions and discussion in Sect. 4.

\section{Methodology}

\subsection{Methodology framework}

The framework for the SVM-based rolling horizon stochastic game model proposed here is shown in Fig. 1.

In China, natural gas supply includes three parts: domestic gas field production, pipeline gas imports and LNG imports. The domestic gas price is still under government regulation, and almost all the contracts of pipeline gas imports are of long-term, with the most significant volatility arising from LNG import prices. As a consequence, in each roll, a SVM regression model is used to forecast the future LNG price based on historical information. The result is taken as the main branch of each scenario tree. As shown in Fig. 2, the forecast result is the LNG price of red nodes (basic nodes) and the corresponding accuracy of the SVM model in the test process is applied as their probability. The probability distribution of other nodes in the scenario tree is obtained based on the basic nodes. After the SVM model in each roll is completed, the decisions of each market participant based on the whole information of the roll can be obtained by the game theoretical model. In the game theoretical model, game players including the SOCs (DP and LI) and private companies (LT) make decisions on their gas supply volume to pursue their maximized individual net profit for each roll, as shown in Fig. 1. The decisions of each market participant based on the whole information of the current roll can be obtained; however, only the plan for first year in each roll (when $r=t$ ) will be implemented practically. Although the decisions made in other years of each roll (when $r \neq t$ ) will not be implemented, they also have impacts on the decision of the first year in each roll (when $r=t$ ) endogenously. At the beginning of each year, the previous year's price information becomes known, and the historical data will be updated and used to train the SVM model in the current year. In this way, a new scenario tree is formed, and a new market equilibrium is obtained from the game model. The integrated model operates roll by roll, with the information updated simultaneously. 


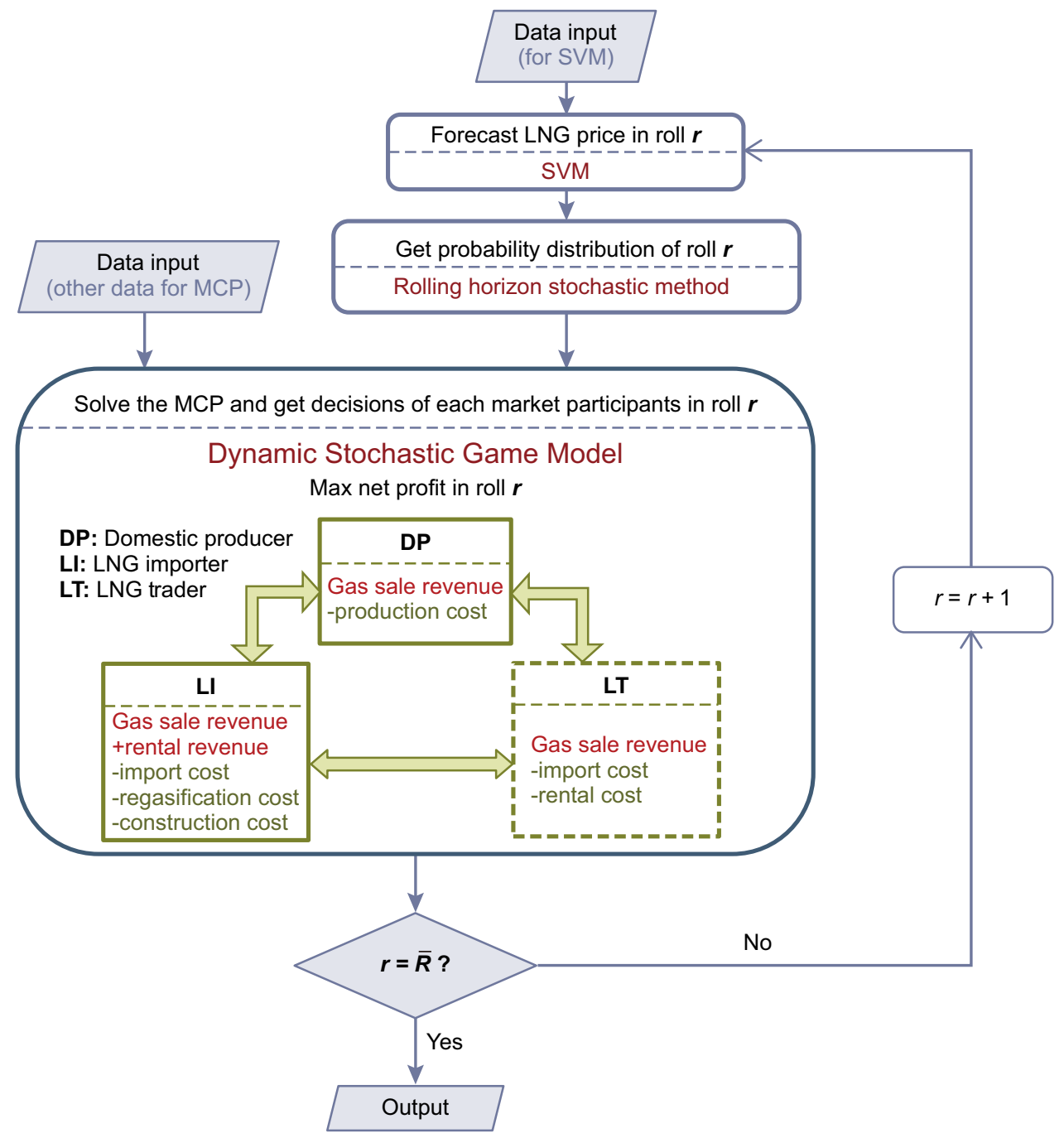

Fig. 1 Model framework



Fig. 2 Comparison of the rolling horizon approach and the traditional approach
As shown in Fig. 2, perfect information of the future probability distribution is necessary for stochastic factors using the traditional binary tree approach, but this is difficult to achieve in practice. Moreover, the future probability distribution is set in advance and cannot be adjusted flexibly even if large fluctuations happen during the planning period. Furthermore, it is difficult to compute efficiently for too many scenarios when the planning period increases to a relatively long time. Finally, some unrealistic scenarios cannot be eliminated efficiently, for example, the green nodes may be unrealistic; however, they will be involved in further computations regardless. In the proposed approach, a machine learning process SVM is used to modify the probability distribution of the LNG price movement in the rolling horizon method. The forecasting result of the SVM method is used to form the main branch of the scenario tree in the rolling horizon approach, and the precision of forecasting generated by its testing process is used to describe 
the probability of the corresponding main branch. Every time when the price information in the rolling horizon method is updated, the new data will be used for training the SVM. Therefore, the price information updated in the rolling horizon method offers new data for SVM learning. As a result, the forecast precision of SVM can be improved and the uncertainties of future conditions can be reduced. Furthermore, the SVM-based rolling horizon method can allow information update and decision adjustment, as well as an endogenous learning process. Therefore, compared with traditional approaches, the proposed approach can show much better performance when faced with future uncertainties.

\subsection{SVM forecast approach}

In order to provide a more convincing and robust result, the SVM method is used to simulate the future LNG price fluctuations. SVM is a supervised machine learning method based on structural risk minimization, which requires a relatively small amount of learning data compared with other machine learning methods. The training process of the SVM method is equivalent to solving a quadratic optimization problem. This property ensures that it will generate a unique and globally optimal solution (Papadimitriou et al. 2014). Consider a data set $\left\{\left(x_{t}, y_{t}\right)\right\}$ in which $x_{t}$ is the input vector at time $t$ and $y_{t}$ is the corresponding output vector which is defined as:

$y_{t}=f\left(x_{t}\right)=w \cdot g\left(x_{t}\right)+b$,

where $g()$ denotes for the function that maps input data $x_{t}$ into a high-dimensional feature space. The weight $\|w\|$ and intercept $\mathrm{b}$ can be obtained by solving the corresponding optimization problem:

$$
\begin{aligned}
& \text { Min } \frac{1}{2}\left\|w^{2}\right\|+C \sum_{t=1}^{n}\left(\xi_{t}^{-}+\xi_{t}^{+}\right) \\
& \text {s.t. } \quad y_{t}-w \cdot g\left(x_{t}\right)-b \leq \varepsilon+\xi_{t}^{-} \\
& w \cdot g\left(x_{t}\right)+b-y_{t} \leq \varepsilon+\xi_{t}^{+} \\
& \xi_{t}^{-}, \xi_{t}^{+} \geq 0,
\end{aligned}
$$

where $\|w\|$ is also called the regularized term, $C$ is denoted as the regularization constant with regard to a unit penalty of error, and $\sum_{t=1}^{n}\left(\xi_{t}^{-}+\xi_{t}^{+}\right)$is the empirical error. When $f\left(x_{t}\right)$ departs from $y_{t}$, SVM would penalize it by means of an $\varepsilon$-insensitive loss function with $2 \varepsilon$ bandwidth:

$$
\left|y_{t}-f\left(x_{t}\right)\right|_{\varepsilon}=\left\{\begin{array}{cc}
0, & \text { if }\left|y_{t}-f\left(x_{t}\right)\right| \leq \varepsilon \\
\left|y_{t}-f\left(x_{t}\right)\right|-\varepsilon, & \text { otherwise. }
\end{array}\right.
$$

Therefore, as the solution to the aforementioned minimization problem, the final SVM for the nonlinear function is of the form:

$f\left(x_{t}\right)=\sum_{t=1}^{n}\left(\theta_{t}-\theta_{t}^{*}\right) K\left(x, x_{t}\right)+b$,

where $\theta_{t}$ and $\theta_{t}$ are the Lagrange multipliers and $K\left(x, x_{t}\right)=$ $g(x) \cdot g\left(x_{t}\right)$ represents a kernel, which is the inner product of vectors $x$ and $x_{t}$ in the space $g(x)$ and $g\left(x_{t}\right)$. A Gaussian basis kernel is often used and is the most powerful one in nonlinear function regression (Yan and Chowdhury 2014).

$K\left(x, x_{t}\right)=e^{-\frac{\left\|x-x_{t}^{2}\right\|}{2 \sigma^{2}}}$.

\subsection{Rolling horizon stochastic method}

In the process of dynamic planning for a certain period, it is difficult to obtain complete relevant information. Moreover, since the reliability of information decreases with time to the forecast date, it is difficult to make credible forecasts relatively far into the future (Čeperić et al. 2017; Odetayo et al. 2017). Considering the imperfect information issue, a rolling horizon method is used to describe the real decision process.

The decision procedure of an SVM-based rolling horizon method is depicted in Fig. 3. In each roll $r$, the price information of the first period (namely, $t=r$ ) is known exactly, while the information of the other two periods (namely, $t=r+1$ and $t=r+2$ ) is unknown. In the next roll $r^{*}\left(r^{*}=r+1\right)$, the second period in roll $r(t=r+1)$ becomes the first period in roll $r^{*}\left(t=r^{*}\right)$. That is, the unknown information of the second period in roll $r$ now becomes known in roll $r^{*}$.

Through the SVM regression method, in each roll, the main branch of the scenario tree is obtained as the red trail shown in Fig. 3. The $\mathrm{LP}_{1,2,1}$ and $\mathrm{LP}_{2,3,1}$ are the predicted results in roll 1. The $p r_{1,2,1}$ (marked as $p$ ) indicates the probability of the forecast result $\mathrm{LP}_{1,2,1}$ occurring. Therefore, the accuracy calculated in the test process of the SVM model is simulated as its probability. In the testing process of the SVM approach, if the forecast result is within 95\%$105 \%$ of the real data of the same period, it is considered as "correct." The accuracy is calculated as the number of "correct" forecasting data divided by the total amount of testing data. So the proportion of "correct" forecasts in testing (accuracy) is extended to describe the likelihood of forecasting correctly (probability). Since the forecast price $\mathrm{LP}_{1,2,1}$ increased by $1.94 \%$ compared with $\mathrm{LP}_{1,1,1}$, the $\mathrm{LP}_{1,2,2}$ is computed symmetrically: decreasing the same percent of $\mathrm{LP}_{1,1,1}$, with a probability of $q$ (equal to $1-p$ ). 




Fig. 3 SVM-based rolling horizon stochastic method

Thus, $p r_{2,3,1}$ is the square of $p r_{1,2,1}$ and $p r_{1,3,1}=p \cdot q$. Similarly, scenario trees are built with each roll.

\subsection{Dynamic game model of China's natural gas market}

\subsubsection{Scenario design}

In this section, four scenarios are set in order to determine the different impacts of the main reforms in the natural gas upstream market and their combined effects.

The first reform is business separation. According to the Smith-Young theorem (Stigler 1951), the expansion of market scale will boost the precise division on the supply side. In practice, there is a corresponding trend of precise division in the Chinese natural gas upstream market: The LNG import volume of CNOOC occupied $67 \%$ and $73.6 \%$ of the total LNG imports in 2013 and 2014, respectively, while its domestic production only occupied around $10 \%$ of the gross production in China. Therefore, there is a possibility that CNOOC will focus more on LNG imports. The second reform is regarding TPA and was implemented at the end of 2014 by the Chinese National Development and Reform Commission (NDRC). In China, the utilization ratio of LNG terminals was only about $51.3 \%$ and $52.3 \%$ in
2014 and 2015, respectively, mainly caused by the weak demand. Because of the monopoly issue and cross-subsidies, the gas price has remained at an excessively high level. TPA is an efficient way to increase competition in the upstream natural gas market. Suppliers will decrease their prices in order to gain market share. Moreover, most LNG import contracts of Chinese state-owned companies are long-term contracts in order to ensure LNG supply. However, the private companies do not have the responsibility to ensure supply security, so their actions are more flexible. Especially from 2015, the LNG spot price has remained at low levels, and private companies can buy LNG at spot prices rather than long-term contracts. On the other hand, in order to maintain market share, SOCs have to follow the downward trend of gas prices. Therefore, the market equilibrium price of natural gas will drop, which will further stimulate its demand. In this way, TPA can improve the efficiency of the utilization of LNG terminals.

In order to identify the different impacts of the reforms and their combined effect, four scenarios are proposed according to different market structures, as shown in Fig. 4.

Scenario 1 Horizontal integration 


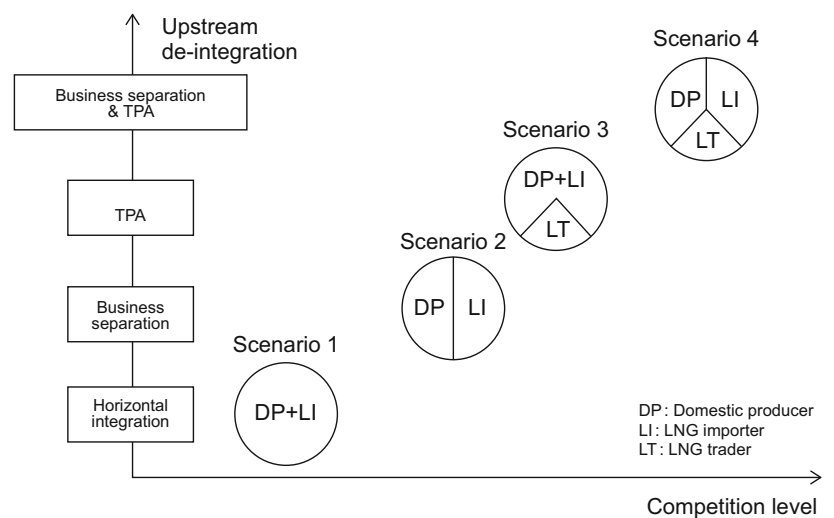

Fig. 4 Structure of natural gas upstream market model

In the first market structure scenario, the whole gas market was monopolized by a horizontally integrated company. The company extracts natural gas from domestic gas fields as well as importing LNG. For example, before the market reform, the three big state-owned companies CNPC, SINOPEC and CNOOC, monopolized both domestic gas fields and LNG terminals. Since there is no competitor in the perfect monopoly market, Scenario 1 is an optimization problem.

Scenario 2 Single policy I (business separation)

In the second scenario, business separation is conducted in the upstream sector: Oligopoly companies DP and LI are in charge of domestic production and LNG imports, respectively. Thus, market equilibrium will be determined by a simultaneous game of two heterogeneous producers DP and LI. For instance, if the business of each stateowned company is specialized, CNPC and SINOPEC will only be in charge of domestic natural gas extraction, while CNOOC is only in charge of the LNG import business.

Scenario 3 Single policy II (third-party access, TPA)

In Scenario 3, TPA is permitted to import LNG by renting facilities. The market equilibrium is codetermined by the TPA together with the original monopolists DP and LI. A natural gas market totally monopolized by stateowned companies will lead to low efficiency or pricing disturbances across the whole industry chain, and TPA is a relatively straightforward and efficient way to introduce a competition mechanism into a monopoly market. Apart from the big three state-owned companies, private companies will be permitted to import LNG from the global market directly.

Scenario 4 Combined policies (business separation and TPA)

In Scenario 4, both business separation and TPA are implemented. In this scenario, after the implementation of business separation, CNPC and SINOPEC become pure domestic producers, while CNOOC is the LNG importer. Then LNG market TPA is permitted and private companies can rent the LNG terminals of the original LNG importer. Compared with the simple TPA scenario (Scenario 3), Scenario 4 can be used to obtain the best market conditions of introducing TPA to improve the market competition level.

\subsubsection{Dynamic game model of China's natural gas market}

On the end-user side, market price is formed through the production competition of game players since the total demand is met by the suppliers jointly. The demand function of the whole market is:

$p=b_{1}+b_{2}\left(q_{1}+q_{2}+q_{3}\right)$,

where $p$ is the natural gas price, and $q_{1}, q_{2}$ and $q_{3}$ are the supply of DP, LI and LT, respectively.

At the supply side, different models are set in each scenario:

\section{Scenario 1 Horizontal integration}

In this scenario, an integrated company owns the domestic gas fields and LNG terminals simultaneously. The objective of the integrated company (the domestic producer and LNG importer, DP + LI) is to maximize its total profit. The total profit is expressed as the revenue from selling natural gas to consumers subtracting the costs from domestic production, pipeline gas imports, LNG imports and regasification, infrastructure construction as well as natural gas transportation, as shown in Eq. (10). In particular, the cost of pipeline gas imports and average transportation cost are included in $\mathrm{PC}_{t}$. Based on the aforementioned assumptions, the integrated company makes decisions on the extraction volume of gas fields $q_{1}$, LNG import volume $q_{2}$ and the expanded regasification capacity $c$, subject to technical and economic constraints. The domestic production and infrastructure construction cannot exceed their upper bounds as shown in Eqs. (11) and (13), respectively. On the other hand, the upper limit of LNG import volume is the sum of the existing and newbuilt receiving capacity as shown in Eq. (12).

$$
\begin{aligned}
& \operatorname{Max} \sum_{s} \sum_{t=r}^{r+\bar{T}-1} \mathrm{PR}_{s}\left[b_{1 t} \sum_{i} q_{i s t r}+b_{2 t}\left(\sum_{i} q_{i s t r}\right)^{2}\right. \\
& \left.-\mathrm{PC}_{t} q_{1 s t r}-\left(\mathrm{GC}_{t}+\mathrm{LP}_{s t r}\right) q_{2 s t r}-\frac{T-t+1}{\mathrm{SP}} \mathrm{RC}_{t} c_{s t r}\right] /(1+d)^{t-1}
\end{aligned}
$$

s.t $\quad q_{1 s t r} \leq \bar{Q}_{t} \quad\left(\lambda_{s t r}\right)$ 
$q_{2 s t r} \leq \overline{\mathrm{G}}_{t}+\sum_{m=1}^{t-1} c_{m s r} \quad\left(\beta_{s t r}\right)$

$c_{s t r} \leq \overline{\mathrm{C}}_{t} \quad\left(\alpha_{s t r}\right)$.

\section{Scenario 2 Business separation}

In the second scenario, gas fields and LNG terminals belong to the domestic producer DP and LNG importer LI, respectively. In Scenario 1, DP and LI are integrated into a monopoly company; therefore, they have a mutual objective, Eq. (10). On the other hand, in Scenario 2, DP and LI become independent and they are aiming at maximizing their own objectives, respectively, Eq. (14) and (16). The market power is thus changed. DP decides the extraction volume $q_{1}$ to maximize its profit, which is expressed as the revenue from selling natural gas to consumers subtracting the cost of production, as shown in Eq. (14). Meanwhile, the production volume cannot exceed the capacity as shown in Eq. (15).

$$
\begin{aligned}
& \operatorname{Max} \sum_{s} \sum_{t=r}^{r+\bar{T}-1} \operatorname{PR}_{s}\left[b_{1 t} q_{1 s t r}+b_{2 t} q_{1 s t r} \sum_{i} q_{i s t r}-\mathrm{PC}_{t} q_{1 s t r}\right] \\
& /(1+d)^{t-1}
\end{aligned}
$$

s.t $\quad q_{1 s t r} \leq \overline{\mathrm{Q}}_{t} \quad\left(\lambda_{s t r}\right)$.

On the other hand, LNG importer LI decides the import volume $q_{2}$ of LNG and the expanded regasification capacity $c$ of each year to maximize its profit. LI's profit is the revenue from selling natural gas to consumers, subtracting the cost of domestic production, LNG import and gasification, and infrastructure construction, as shown in Eq. (16). The upper limit of LNG import volume is the sum of the existing and new-built receiving capacity as shown in Eq. (17). Infrastructure construction cannot surpass its capacity as per Eq. (18).

$$
\begin{aligned}
& \operatorname{Max} \sum_{s} \sum_{t=r}^{r+\bar{T}-1} \mathrm{PR}_{s}\left[b_{1 t} q_{2 s t r}+b_{2 t} q_{2 s t r} \sum_{i} q_{i s t r}\right. \\
& \left.-\left(\mathrm{GC}_{t}+\mathrm{LP}_{s t r}\right) q_{2 s t r}-\frac{T-t+1}{\mathrm{SP}} \mathrm{RC}_{t} c_{s t r}\right] /(1+d)^{t-1} \\
& \text { s.t } \quad q_{2 s t r} \leq \overline{\mathrm{G}}_{t}+\sum_{m=1}^{t-1} c_{m s r}\left(\beta_{s t r}\right) \\
& c_{s t r} \leq \overline{\mathrm{C}}_{t} \quad\left(\alpha_{s t r}\right) .
\end{aligned}
$$

Scenario 3 Third-party access (TPA)

In Scenario 3, there is an integrated company (the domestic producer and LNG importer, DP $+\mathrm{LI}$ ) as described in Scenario 1 and a new market entrant LT. The integrated company pursues the maximum profit, which equals the revenue from selling natural gas to consumers and leasing surplus regasification capacity to LT, subtracting the cost of domestic production, LNG import and gasification, and infrastructure construction, as shown in Eq. (19). In this scenario, the integrated company decides the domestic production, LNG imports and LNG terminal construction, as well as the regasification capacity leasing to LT. However, the LT is subject to some constraints: the domestic production capacity bounds (20) and the infrastructure construction capacity constraint (22). Moreover, the sum of LNG import volumes from LT and LI cannot exceed the total amount of the existing and new-built receiving capacity as shown in Eq. (21).

$$
\begin{aligned}
& \operatorname{Max} \sum_{s} \sum_{t=r}^{r+\bar{T}-1} \mathrm{PR}_{s}\left[b_{1 t} \sum_{i} q_{i s t r}+b_{2 t}\left(\sum_{i} q_{i s t r}\right)\left(\sum_{j} q_{j s t r}\right)\right. \\
& \quad-\mathrm{PC}_{t} q_{i s t r}-\left(\mathrm{GC}_{t}+\mathrm{LP}_{s t r}\right) q_{2 s t r}-\frac{T-t+1}{\mathrm{SP}} \mathrm{RC}_{t} c_{s t r} \\
& \left.\quad+\left(r t_{s t r}-\mathrm{GC}_{t}\right) q r_{3 s t r}\right] /(1+d)^{t-1} \\
& \text { s.t } \quad q_{1 s t r} \leq \overline{\mathrm{Q}}_{t} \quad\left(\lambda_{s t r}\right) \\
& q_{2 s t r}+q r_{3 s t r} \leq \overline{\mathrm{G}}_{t}+\sum_{m=1}^{t-1} c_{m s r} \quad\left(\beta_{s t r}\right) \\
& c_{s t r} \leq \overline{\mathrm{C}}_{t} \quad\left(\alpha_{s t r}\right) .
\end{aligned}
$$

The new market entrant LT also pursues its own maximum profit by deciding the LNG terminal capacity rented from the integrated company and the import volume. LT's profit is the revenue from selling natural gas to consumers subtracting the cost of the rental fee and import cost as shown in Eq. (23). Meanwhile, the LT cannot import exceeding its capacity, as depicted in Eq. (24).

$$
\begin{gathered}
\operatorname{Max} \sum_{s} \sum_{t=r}^{r+\bar{T}-1} \mathrm{PR}_{s}\left[b_{1 t} q_{3 s t r}+b_{2 t} q_{3 s t r} \sum_{j} q_{j s t r}\right. \\
\left.-\left(r t_{s t r}+\mathrm{LP}_{s t r}\right) q_{3 s t r}\right] /(1+d)^{t-1} \\
\text { s.t } \quad q_{2 s t r}+q_{3 s t r} \leq \bar{G}_{t}+\sum_{m=1}^{t-1} c_{m s r} \quad\left(\gamma_{s t r}\right) .
\end{gathered}
$$

The rent for regasification capacity of LI is codetermined by the owner and the renter through the marketclearing condition, as shown in Eq. (25).

$q_{2 s t r}=q_{3 s t r} \quad\left(r t_{s t r}\right)$.

Scenario 4 Business separation \& LNG market TPA

In Scenario 4, both business separation and TPA are introduced. There are three companies competing in the 
market, including the domestic producer (DP), LNG importer (LI) and new market entrant (LNG trader, LT).

The domestic producer DP decides the extraction volume of natural gas to maximize its profit which is the revenue from selling natural gas to consumers subtracting the cost of production, as shown in Eq. (26). Meanwhile, the production cannot exceed the capacity as shown in Eq. (27).

$\operatorname{Max} \sum_{s} \sum_{t=r}^{r+\bar{T}-1} \mathrm{PR}_{s}\left[b_{1 t} q_{1 s t r}+b_{2 t} q_{1 s t r} \sum_{j} q_{j s t r}-\mathrm{PC}_{t} q_{1 s t r}\right] /(1+d)^{t-1}$

s.t $\quad q_{1 s t r} \leq \overline{\mathrm{Q}}_{t} \quad\left(\lambda_{s t r}\right)$.

The original LNG importer LI makes decisions on both the import volume of LNG and the expanded regasification capacity each year. LI's profit is the revenue from selling natural gas to consumers and leasing surplus regasification capacity to LT, subtracting the cost from domestic production, LNG imports and gasification, and infrastructure construction, as shown in Eq. (28). The sum of LNG import volume from LT and LI cannot exceed the total amount of the existing and new-built receiving capacity as Eq. (29). There is also an upper bound for infrastructure construction as shown in Eq. (30).

$$
\begin{aligned}
& \operatorname{Max} \sum_{s} \sum_{t=r}^{r+\bar{T}-1} \mathrm{PR}_{s}\left[b_{1 t} q_{2 s t r}+b_{2 t} q_{2 s t r} \sum_{j} q_{j s t r}\right. \\
& -\left(\mathrm{GC}_{t}+\mathrm{LP}_{s t r}\right) q_{2 s t r}-\frac{T-t+1}{\mathrm{SP}} \mathrm{RC}_{t} c_{s t r} \\
& \left.\quad+\left(r t_{s t r}-\mathrm{GC}_{t}\right) q r_{3 s t r}\right] /(1+d)^{t-1} \\
& \text { s.t } \quad q_{2 s t r}+q r_{3 s t r} \leq \overline{\mathrm{G}}_{t}+\sum_{m=1}^{t-1} c_{m s r} \quad\left(\beta_{s t r}\right) \\
& c_{s t r} \leq \overline{\mathrm{C}}_{t} \quad\left(\alpha_{s t r}\right) .
\end{aligned}
$$

Similar to Scenario 3, the new market entrant LT rents LNG terminals from the original $\mathrm{LNG}$ importer LI. Its profit is the revenue from selling natural gas to consumers subtracting the cost of the rental fee and import cost as shown in Eq. (31). Meanwhile, the LT cannot import more than its capacity, as shown in Eq. (32).

$$
\begin{gathered}
\operatorname{Max} \sum_{s} \sum_{t=r}^{r+\bar{T}-1} \operatorname{PR}_{s}\left[\mathrm{~b}_{1 t} q_{3 s t r}+b_{2 t} q_{3 s t r} \sum_{j} q_{j s t r}\right. \\
\left.-\left(r t_{s t r}+\mathrm{LP}_{s t r}\right) q_{3 s t r}\right] /(1+d)^{t-1} \\
\text { s.t } \quad q_{2 s t r}+q_{3 s t r} \leq \bar{G}_{t}+\sum_{m=1}^{t-1} c_{m s r} \quad\left(\gamma_{s t r}\right) .
\end{gathered}
$$

As for the rent for regasification capacity of LNG importer LI, it is also generated by the game between the owner LI and the renter LT through a market-clearing condition, as shown in Eq. (33).

$q_{2 s t r}=q_{3 s t r} \quad\left(r t_{s t r}\right)$.

\subsection{Tools}

The SVM regression model is accomplished in $\mathrm{R}$ using the e1071 package. $\mathrm{R}$ is an integrated suite of software facilities for data manipulation, calculation and graphical display (Venables et al. 2016). The e1071 package is designed for machine learning and data mining.

The non-cooperative game theoretical complementarity model is developed in the general algebraic modeling system (GAMS) as a mixed complementarity problem (MCP) (Rosenthal 2004). Gabriel et al. (2001), Hobbs (2001) and Tung et al. (2013) have proved the mathematical properties of existence and uniqueness for the MCP solution. In this paper, the MCP problem is solved using the PATH solver. It takes $214 \mathrm{~s}$ in total to solve this problem on a computer with i7 $2.5 \mathrm{GHZ}$ CPU and $4 \mathrm{~GB}$ memory. GAMS is a platform that uses algebraic language and efficient solvers for analyzing complex, large-scale linear, nonlinear, integer and complementarity problems (Rosenthal 2004). The PATH solver is a Newton-based algorithm for solving complementarity problems.

\section{Result}

\subsection{Data}

In this section, the numerical simulation using the SVMbased rolling horizon game model is described based on the data of China's natural gas market (shown in Table 1) and the demand function is proposed based on assumption.

A 1-year deposit rate with a prospective premium is used as the discount rate $\mathrm{d}$, stipulated as $3.5 \%$, and the production costs of heterogeneous suppliers are also different. Domestic producer DP is faced with a composite unit production cost $\mathrm{PC}$, which consists of the extraction cost, transportation cost and long-term pipeline gas import cost. Apart from the feed stock cost (mainly long-term LNG), the production costs GC that the original LNG importer LI is faced with are the unit regasification cost and unit infrastructure construction cost, while the production cost for LT is the LNG terminal rent. The feed stock for LI and LT is LNG, and the price is obtained by the SVM regression method using the data of CIF price of LNG with a transportation adjustment.

In SVM forecasting, since no Chinese monthly LNG import price can be directly found, the monthly data of Japan's average LNG import price (from IEA database) are 
Table 1 Data

\begin{tabular}{|c|c|c|c|c|c|c|c|c|}
\hline \multirow[t]{2}{*}{ Parameter } & \multicolumn{8}{|c|}{ Value in period $t$} \\
\hline & 1 & 2 & 3 & 4 & 5 & 6 & 7 & 8 \\
\hline$d$ (discount rate) & $3.5 \%$ & & & & & & & \\
\hline $\mathrm{PC}$ (unit production cost of gas field, $\mathrm{RMB} / \mathrm{m}^{3}$ ) & 1.8 & & & & & & & \\
\hline $\mathrm{GC}$ (unit regasification cost, $\mathrm{RMB} / \mathrm{m}^{3}$ ) & 0.3 & & & & & & & \\
\hline $\mathrm{RC}$ (unit cost of terminal construction, $\mathrm{RMB} / \mathrm{m}^{3}$ ) & 1.2 & & & & & & & \\
\hline$\overline{\mathrm{R}}$ (initial regasification capacity, bcm) & 50 & & & & & & & \\
\hline SP (life span of LNG terminals, year) & 20 & & & & & & & \\
\hline$b_{2}$ (slope of demand function) & -0.05 & & & & & & & \\
\hline$b_{1}$ (intercept of demand function) & 5 & 5 & 6 & 6 & 6 & 6 & 6 & 6 \\
\hline$\overline{\mathrm{Q}}$ (domestic production capacity, bcm) & 184 & 195 & 216 & 220 & 237 & 238 & 240 & 259 \\
\hline$\overline{\mathrm{C}}$ (infrastructure construction capacity, bcm) & 50 & 50 & 50 & 80 & 80 & 80 & 80 & 80 \\
\hline
\end{tabular}

used for regression. Japan is the biggest LNG importer in the world and geographically close to China; therefore, most Chinese LNG contracts take Japanese prices as a reference or benchmark. The time span of the data is from 1996 to 2015. Thus, the total sample size is 240, among which, according to the rule of thumb, $70 \%$ of the total data is used for training, $15 \%$ for testing, and $15 \%$ for forecasting. In the rolling horizon approach, the updated price data are calculated based on the forecasts of Exxon Mobil (2016).

\subsection{Result}

This section presents the results obtained from the SVMbased rolling horizon stochastic game model. The results are reported from three aspects: (1) facility capacity; (2) trading volume; and (3) benefit of LNG market reform.

\subsubsection{Facility capacity}

As shown in Fig. 5, with the increase in market competition, the cumulative regasification capacity of LNG terminals increases as well. In Scenarios 2, 3 and 4, the regasification capacity increased by 88.4, 203.6 and

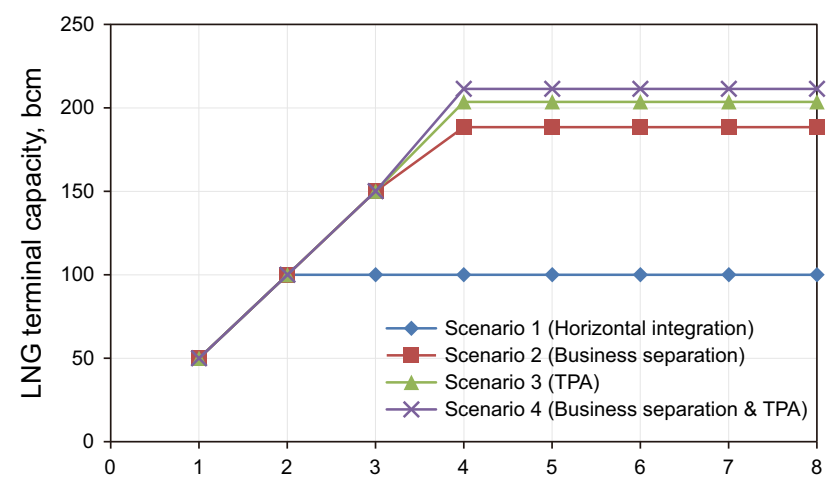

Fig. 5 Dynamic planning of LNG terminal construction
$211.4 \%$, respectively, compared with the monopoly scenario. If only one reform is implemented, TPA can work better than business separation in terms of the impact on LNG terminal construction. However, if both of the reform policies are implemented simultaneously, the cumulative regasification capacity only rises by $3.83 \%$ compared to the single policy II (TPA), indicating an overlapping effect of the two policies.

\subsubsection{Trading volume}

The trading volume of each game player is shown in Fig. 6. Since the cost of domestic production is much lower than LNG import and regasification, domestic producer DP would extract natural gas at full capacity in each scenario. After business separation, the trading volume of LI is almost doubled compared with the complete monopoly scenario.

When TPA is introduced in the LNG import market, the allocations of LNG trading volume between LI and LT are much different to the last two scenarios. In Scenario 3, the LNG imports of the integrated company (Scenario 3-LI)

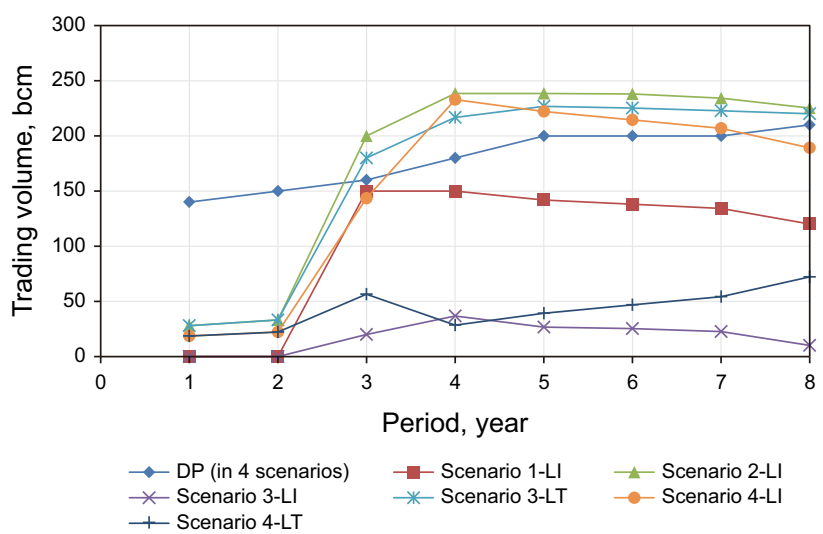

Fig. 6 Dynamic planning of natural gas trading volume in the three scenarios 
are below $40 \mathrm{bcm}$, while the LNG import volume of LT is about 4 times more than the integrated company. On the other hand, in Scenario 4, the LNG import volume of LI is far more than the LT's trading volume. Since the payment for LT renting LI's LNG terminals is decided by marketclearing conditions, the player with stronger market power would benefit more in the negotiation of the rent. In Scenario 3, LI is only a sector of the integrated company, which means the integrated company can obtain its market share from domestic production. Therefore, the integrated company will use the LNG terminal less and lease the capacity to LT to obtain more profits. The results show that the integrated company gets a payment of 449.2 billion RMB from surplus regasification capacity leasing using its market power. In Scenario 4, LI is an independent company which has less power than the integrated company in Scenario 3. To keep its market share, LI will not lease out all of its regasification capacity; as a result, LI can only get a total rent of 123.6 billion RMB from LT.

\subsubsection{Benefit of LNG market reform}

To quantitatively determine the effect of market reforms, the social welfare is defined as the sum of producers' profit and consumers' surplus. The consumers' surplus is calculated by:

$\mathrm{CS}=\int_{0}^{Q^{*}} P(Q) \mathrm{d} Q-P^{*} Q^{*}$,

where $Q$ is the total trading volume and $P$ is the market price natural gas. * denotes the market equilibrium conditions.

The result of market equilibrium and total producers' profit are shown in Fig. 7; in different market reform scenarios with more and more competition, the price is decreasing and the total trading volume and social welfare are increasing.

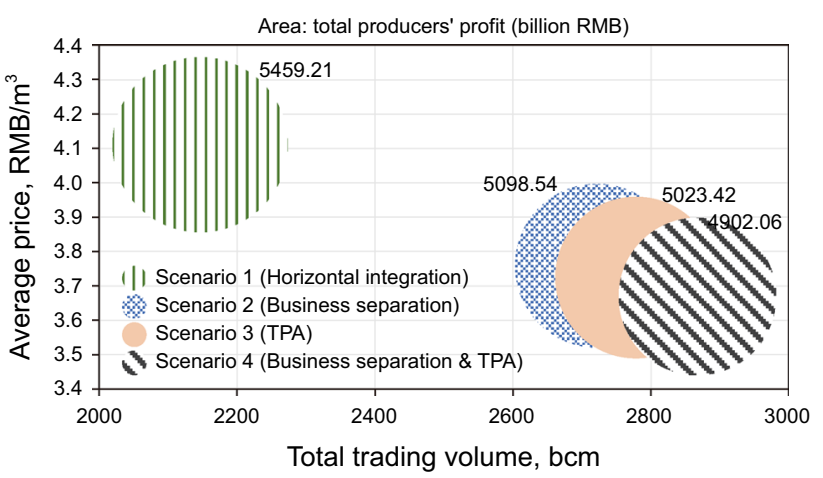

Fig. 7 Market equilibrium and total producers' profit in four scenarios
Compared with Scenario 1, the prices of Scenario 2, Scenario 3 and Scenario 4 decreased by 8.56, 9.41 and $10.7 \%$, respectively; however, their total trading volume increased by $26.3,28.9$ and $33.0 \%$, respectively. In Scenario 1 , since the whole market is monopolized by an integrated company, the monopolist would maintain production at a relatively low level and charge consumers a relatively high price to obtain an excessive profit. As the number of market participants increases, the market power of each company is undermined. If one of the game players takes the former complete monopoly price, the other players would offer a lower price to dominate the market. Therefore, the total production will increase and the equilibrium price will drop through the production competition.

As shown in the pie charts in Fig. 8, the total amount and constitution of social welfare have also changed. Compared with Scenario 1, consumers' surplus in Scenario 2, Scenario 3 and Scenario 4 increased by 61.2, 68.6 and $79.0 \%$, respectively, which is mirrored by the decrease in producers' profit. At the same time, the total social welfare raised by $10.2,10.9$ and $12.0 \%$, respectively. As the market competition increases, the consumers will get more benefits, while the profit of producers is undermined, and thus the total social welfare is improved. Therefore, a single policy (in Scenario 2 and Scenario 3) is Pareto improving compared with the complete monopoly scenario (Scenario 1), and the combined policies (Scenario 4) is Pareto improving compared with a single policy scenario. From the aspect of total social welfare, combined policies will make a better market equilibrium.

In Scenario 3, if the TPA is implemented separately, the original LNG importer LI will suffer great losses. The profit of LI in Scenario 3 only equals $20.2 \%$ of Scenario 4. However, in Scenario 4, the profit and production of the new entrant LT is $79.0 \%$ lower than that in Scenario 3, the

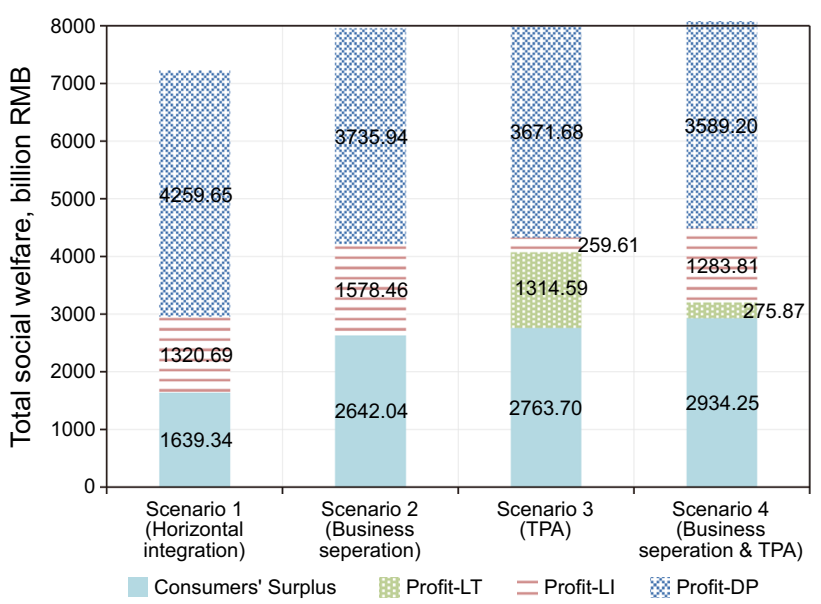

Fig. 8 Social welfare makeup in four scenarios 
profit of domestic producer DP also dropped by $2.25 \%$, and the total profit of producers decreased by $1.85 \%$.

\section{Conclusions and discussion}

To promote the consumption of natural gas in China, market reforms will play a crucial role. The comparison of the impacts of two single policy scenarios (business separation and TPA) and their cross-effects are made using an SVM-based rolling horizon stochastic game model in the present study.

(1) From the aspects of infrastructure capacity, with the increase in market competition, the cumulative regasification capacity of LNG terminals increases as well. When a single reform policy is implemented, business separation and TPA, the regasification capacity will increase by $88.4 \%$ and $203.6 \%$ compared with the complete monopoly scenario. Furthermore, when the two reform policies are implemented simultaneously, the capacity only increases by $3.83 \%$ compared with the TPA scenario. This may be caused by the overlap effect of two policies on LNG infrastructure construction.

(2) As the marketization level increases, the trading volume of DP is maintained; on the other hand, the trading volumes of LI and LT increased tremendously. The stability of DP's trading volume comes from its relatively low production cost. After business separation, the trading volume of LI is more than doubled compared with the complete monopoly scenario due to the change in market power.

(3) When the TPA is permitted in Scenario 3 and Scenario 4, LI will lend surplus LNG receiving capacity to entrant LT. In China, private companies usually have exclusive local distribution channels for natural gas, while SOCs have to transport and distribute natural gas nationwide. Private companies can make more profit than SOCs by saving distribution cost in LNG trading. The comprehensive production cost (including distribution cost) of SOC (LI) is $0.3 \mathrm{RMB} / \mathrm{m}^{3}$, while the cost of private company LT is around $0.2 \mathrm{RMB} / \mathrm{m}^{3}$. Although SOCs own LNG terminals, private companies have the comparative advantage in LNG trading. Therefore, the SOCs have the incentive to obtain extra profit by lending capacity to private companies and collect the rent fee rather than utilizing the capacity by themselves, and the private companies are also willing to allot parts of their profit as renting fee to rent the SOCs' LNG terminal capacity. A win-win situation is reached, and the utilization ratio of LNG terminals is thus improved.

(4) Moreover, although the TPA is permitted in both Scenario 3 and Scenario 4, the allocations of LNG trading volume between LI and LT are significantly different. With TPA, the LNG imports of the integrated company are below $50 \mathrm{bcm}$, while the LNG import volume of LT is about four times more than the integrated company. When the two policies are both implemented simultaneously, the LNG import volume of LI is more than twice the LT's trading volume. This dramatic difference is caused by the different market power of the leasers in the two scenarios. The total rent obtained by the leaser in Scenario 3 is $263.4 \%$ more compared to Scenario 4.

(5) As the market competition increases, the equilibrium price and producers' total profit decreased, while the total trading volume, consumers' surplus and social welfare increased. The total social welfare increased by $10.2,10.9$ and $12.0 \%$ in Scenario 2, Scenario 3 and Scenario 4, respectively, compared with Scenario 1. Therefore, a single policy (in Scenario 2 and Scenario 3) is Pareto improving compared with the complete monopoly scenario (Scenario 1), and the combined policies (Scenario 4) is Pareto improving compared with a single policy scenario. From the aspect of total social welfare, combined policies will make a better market equilibrium, because as the number of market participants increases, the market power of each company is undermined and consumers' market power is enhanced.

(6) Furthermore, the profit of LI in Scenario 3 is only equal to $20.2 \%$ of that in Scenario 4. As is aforementioned, LT has cost advantages compared with LI, when TPA is introduced, LT will lower the market price, and other suppliers have to follow the downward trend. LI will lend most regasification capacity to LT to collect the rental income rather than directly import with a relatively high cost. However, given the situation that SOCs will suffer great loss after only the TPA is implemented, it may bring about a social acceptability issue on market reform implementation. If business separation and TPA are both implemented simultaneously in Scenario 4 , the profit and production of the new entrant LT is 79.0\% lower than that in Scenario 3. Since DP, LI, LT become independent companies, LI has to keep its market share to ensure its market power. Therefore, LT cannot rent as much capacity as in Scenario 3. Obviously, the investors would prefer the single policy of TPA rather than combined policies. Therefore, from the aspect of diversity of LNG importer and nurturing new market participants, the 
single policy of TPA will play a more effective role than combined policies.

Acknowledgement The authors gratefully acknowledge the financial support of the National Natural Science Foundation of China (Grant No. 71774171) and Science Foundation of China University of Petroleum, Beijing (No. 2462017YB11).

Open Access This article is distributed under the terms of the Creative Commons Attribution 4.0 International License (http://creative commons.org/licenses/by/4.0/), which permits unrestricted use, distribution, and reproduction in any medium, provided you give appropriate credit to the original author(s) and the source, provide a link to the Creative Commons license, and indicate if changes were made.

\section{Appendix}

\section{A. KKT conditions for each scenario in rolling horizon approach in Sect. 2.4}

The MCP for Scenario 1 consists of Karush-Kuhn-Tucker (KKT) conditions A.1-A.3: A.1 is related to the decision variable of domestic producer DP, while A.2 and A.3 are related to the decision variables of LNG importer LI.

$$
\begin{aligned}
0 \leq & -\mathrm{PR}_{s t r}\left(b_{1 t}+2 b_{2 t} \sum_{i} q_{i s t r}-\mathrm{PC}_{t}\right) \\
& /(1+d)^{t-1}-\lambda_{s t r} \perp q_{1 s t r} \geq 0 \\
0 \leq & -\mathrm{PR}_{s t r}\left(b_{1 t}+2 b_{2 t} \sum_{i} q_{i s t r}-\mathrm{GC}_{t}-\mathrm{LP}_{s t r}\right) \\
& /(1+d)^{t-1}-\beta_{s t r} \perp q_{2 s t r} \geq 0 \\
0 \leq & \mathrm{PR}_{s t r} \mathrm{RC}_{t}+k_{1} \sum_{s=1}^{4} \sum_{y \geq r} \sum_{n \leq x} \beta_{s x y} \\
& +l_{1} k_{2}\left(\beta_{s x y}+\beta_{1(r+2) r}+\beta_{2(r+2) r}\right) \\
& +l_{2} k_{2}\left(\beta_{s x y}+\beta_{3(r+2) r}+\beta_{4(r+2) r}\right) \\
& +k_{3} \beta_{s t r}-\alpha_{s t r} \perp c_{s t r} \geq 0 .
\end{aligned}
$$

The MCP for Scenario 2 consists of KKT conditions A.4-A.6: A.4 is related to the decision variable of domestic producer DP, while A.5 and A.6 are related to the decision variables of LNG importer LI.

$$
\begin{aligned}
& 0 \leq-\mathrm{PR}_{s t r}\left[b_{1 t}+b_{2 t}\left(2 q_{1 s t r}+q_{2 s t r}\right)-\mathrm{PC}_{t}\right] \\
& /(1+d)^{t-1}-\lambda_{s t r} \perp q_{1 s t r} \geq 0 \\
& 0 \leq-\mathrm{PR}_{s t r}\left[b_{1 t}+b_{2 t}\left(q_{1 s t r}+2 q_{2 s t r}\right)-\mathrm{GC}_{t}-\mathrm{LP}_{s t r}\right] \\
& \quad /(1+d)^{t-1}-\beta_{s t r} \perp q_{2 s t r} \geq 0
\end{aligned}
$$

$$
\begin{aligned}
0 \leq & \mathrm{PR}_{s t r} \mathrm{RC}_{t}+k_{1} \sum_{s=1}^{4} \sum_{y \geq r} \sum_{n \leq x} \beta_{s x y} \\
& +l_{1} k_{2}\left(\beta_{s x y}+\beta_{1(r+2) r}+\beta_{2(r+2) r}\right) \\
& +l_{2} k_{2}\left(\beta_{s x y}+\beta_{3(r+2) r}+\beta_{4(r+2) r}\right) \\
& +k_{3} \beta_{s t r}-\alpha_{s t r} \perp c_{s t r} \geq 0 .
\end{aligned}
$$

The MCP for Scenario 3 consists of market-clearing conditions (25) along with KKT conditions A.7-A.11: A.7 is related to the decision variable of domestic producer DP; A.8, A.10 and A.11 are related to the decision variables of LNG importer LI; and A.9 is related to the decision variable of LNG trader LT.

$$
\begin{aligned}
& 0 \leq-\mathrm{PR}_{s t r}\left[b_{1 t}+b_{2 t}\left(2 q_{1 s t r}+2 q_{2 s t r}+q_{3 s t r}\right)-\mathrm{PC}_{t}\right] \\
& \quad /(1+d)^{t-1}-\lambda_{s t r} \perp q_{1 s t r} \geq 0 \\
& 0 \leq-\mathrm{PR}_{s t r}\left[b_{1 t}+b_{2 t}\left(2 q_{1 s t r}+2 q_{2 s t r}+q_{3 s t r}\right)-\mathrm{GC}_{t}-\mathrm{LP}_{s t r}\right] \\
& \quad /(1+d)^{t-1}-\beta_{s t r} \perp q_{2 s t r} \geq 0
\end{aligned}
$$

$$
\begin{gathered}
0 \leq-\mathrm{PR}_{s t r}\left[b_{1 t}+b_{2 t}\left(q_{1 s t r}+q_{2 s t r}+2 q_{3 s t r}\right)-r t_{s t r}-\mathrm{LP}_{s t r}\right] \\
/(1+d)^{t-1}-\beta_{s t r} \perp q_{3 s t r} \geq 0
\end{gathered}
$$$$
0 \leq-\left(r t_{s t r}-\mathrm{GC}_{t}\right) /(1+d)^{t-1}-\beta_{s t r} \perp q r_{3 s t r} \geq 0
$$$$
0 \leq \mathrm{PR}_{s t r} \mathrm{RC}_{t}+k_{1} \sum_{s=1}^{4} \sum_{y \geq r} \sum_{n \leq x} \beta_{s x y}
$$$$
+l_{1} k_{2}\left(\beta_{s x y}+\beta_{1(r+2) r}+\beta_{2(r+2) r}\right)
$$$$
+l_{2} k_{2}\left(\beta_{s x y}+\beta_{3(r+2) r}+\beta_{4(r+2) r}\right)
$$$$
+k_{3} \beta_{\text {str }}-\alpha_{\text {str }} \perp c_{s t r} \geq 0 \text {. }
$$

The MCP for Scenario 4 consists of market-clearing conditions (33) along with KKT conditions A.12-A.16: A.12 is related to the decision variable of domestic producer DP; A.13, A.15 and A.16 are related to the decision variables of LNG importer LI; and A.14 is related to the decision variable of LNG trader LT.

$$
\begin{aligned}
& 0 \leq-\mathrm{PR}_{s t r}\left[b_{1 t}+b_{2 t}\left(2 q_{1 s t r}+q_{2 s t r}+q_{3 s t r}\right)-\mathrm{PC}_{t}\right] \\
& /(1+d)^{t-1}-\lambda_{s t r} \perp q_{1 s t r} \geq 0 \\
& \quad(\mathrm{~A} .12) \\
& 0 \leq-\mathrm{PR}_{s t r}\left[b_{1 t}+b_{2 t}\left(q_{1 s t r}+2 q_{2 s t r}+q_{3 s t r}\right)-\mathrm{GC}_{t}-\mathrm{LP}_{s t r}\right] \\
& /(1+d)^{t-1}-\beta_{s t r} \perp q_{2 s t r} \geq 0
\end{aligned}
$$




$$
\begin{aligned}
0 \leq & -\mathrm{PR}_{s t r}\left[b_{1 t}+b_{2 t}\left(q_{1 s t r}+q_{2 s t r}+2 q_{3 s t r}\right)\right. \\
& \left.-r t_{\mathrm{str}}-\mathrm{LP}_{s t r}\right] /(1+d)^{t-1}-\beta_{s t r} \perp q_{3 s t r} \geq 0 \\
0 \leq & -\left(r t_{s t r}-\mathrm{GC}_{t}\right) /(1+d)^{t-1}-\beta_{s t r} \perp q r_{3 s t r} \geq 0 \\
0 \leq & \mathrm{PR}_{s t r} \mathrm{RC}_{t}+k_{1} \sum_{s=1}^{4} \sum_{y \geq r} \sum_{n \leq x} \beta_{s x y} \\
& +l_{1} k_{2}\left(\beta_{s x y}+\beta_{1(r+2) r}+\beta_{2(r+2) r}\right) \\
& +l_{2} k_{2}\left(\beta_{s x y}+\beta_{3(r+2) r}+\beta_{4(r+2) r}\right) \\
& +k_{3} \beta_{s t r}-\alpha_{s t r} \perp c_{s t r} \geq 0 .
\end{aligned}
$$

Since the second derivatives of objectives are nonnegative, the individual optimization problems are convex.

\section{References}

Ahmadian Behrooz H, Boozarjomehry RB. Dynamic optimization of natural gas networks under customer demand uncertainties. Energy. 2017;134(Supplement C):968-83. https://doi.org/10. 1016/j.energy.2017.06.087.

Arano KG, Blair BF. An ex-post welfare analysis of natural gas regulation in the industrial sector. Energy Econ. 2008;30(3):789-806. https://doi.org/10.1016/j.eneco.2007.07.003.

Breton M, Vencatachellum D, Zaccour G. Dynamic R\&D with strategic behavior. Comput Oper Res. 2006;33(2):426-37. https://doi.org/10.1016/j.cor.2004.06.014.

Čeperić E, Žiković S, Čeperić V. Short-term forecasting of natural gas prices using machine learning and feature selection algorithms. Energy. 2017;140(Part 1):893-900. https://doi.org/10.1016/j. energy.2017.09.026.

De Wolf D, Smeers Y. A stochastic version of a Stackelberg-NashCournot equilibrium model. Manag Sci. 1997;43(2):190-7. https://doi.org/10.1287/mnsc.43.2.190.

Devine MT, Gabriel SA, Moryadee S. A rolling horizon approach for stochastic mixed complementarity problems with endogenous learning: application to natural gas markets. Comput Oper Res. 2016;68:1-15. https://doi.org/10.1016/j.cor.2015.

Egging R, Gabriel SA, Holz F, Zhuang J. A complementarity model for the European natural gas market. Energy Policy. 2008;36(7):2385-414. https://doi.org/10.1016/j.enpol.2008.01.044.

Egging R, Holz F, Gabriel SA. The world gas model: a multi-period mixed complementarity model for the global natural gas market. Energy. 2010;35(10):4016-29. https://doi.org/10.1016/j.energy. 20.

Feijoo F, Huppmann D, Sakiyama L, Siddiqui S. North American natural gas model: impact of cross-border trade with Mexico. Energy. 2016;112(Supplement C):1084-95. https://doi.org/10. 1016/j.energy.2016.06.133.

Gabriel SA, Kydes AS, Whitman P. The national energy modeling system: a large-scale energy-economic equilibrium model. Oper Res. 2001;49:14-25. https://doi.org/10.1287/opre.49.1.14.11195.

Gabriel SA, Rosendahl KE, Egging R, Avetisyan HG, Siddiqui S. Cartelization in gas markets: studying the potential for a "Gas OPEC". Energy Econ. 2012;34(1):137-52. https://doi.org/10. 1016/j.eneco.2011.05.014.

Gong C, Tang K, Zhu K, Hailu A. An optimal time-of-use pricing for urban gas: a study with a multi-agent evolutionary game-theoretic perspective. Appl Energy. 2016;163(Supplement C):283-94. https://doi.org/10.1016/j.apenergy.2015.
Gordon DV, Gunsch K, Pawluk CV. A natural monopoly in natural gas transmission. Energy Econ. 2003;25(5):473-85. https://doi. org/10.1016/s0140-9883(03)00057-4.

Guigues V, Sagastizábal C, Zubelli JP. Robust management and pricing of liquefied natural gas contracts with cancelation options. J Optim Theory Appl. 2014;161(1):179-98. https://doi. org/10.1007/s10957-013-0309-5.

Hobbs BE. Linear complementarity models of Nash-Cournot competition in bilateral and POOLCO power markets. IEEE Trans Power Syst. 2001;16(2):194-202. https://doi.org/10.1109/59.918286.

Lise W, Hobbs BF, van Oostvoorn F. Natural gas corridors between the EU and its main suppliers: simulation results with the dynamic GASTALE model. Energy Policy. 2008;36(6):1890-906. https:// doi.org/10.1016/j.enpol.2008.01.042.

Lorenczik S, Panke T. Assessing market structures in resource markets - an empirical analysis of the market for metallurgical coal using various equilibrium models. Energy Econ. 2016;59:179-87. https://doi.org/10.1016/j.eneco.2016.07.007.

Odetayo B, MacCormack J, Rosehart WD, Zareipour H. A sequential planning approach for distributed generation and natural gas networks. Energy. 2017;127(Supplement C):428-37. https://doi. org/10.1016/j.energy.2017.03.118.

Paltsev S, Zhang D. Natural gas pricing reform in China: Getting closer to a market system? Energy Policy. 2015;86(Supplement C):43-56. https://doi.org/10.1016/j.enpol.2015.06.027.

Panapakidis IP, Dagoumas AS. Day-ahead natural gas demand forecasting based on the combination of wavelet transform and ANFIS/genetic algorithm/neural network model. Energy. 2017;118(3):231-45. https://doi.org/10.1016/j.energy.2016.12.033.

Papadimitriou T, Gogas P, Stathakis E. Forecasting energy markets using support vector machines. Energy Econ. 2014;44(Supplement C):135-42. https://doi.org/10.1016/j.eneco.2014.03.017.

Rosenthal RE. GAMS- a user's guide. 2004.

Stigler GJ. The division of labor is limited by the extent of the market. J Polit Econ. 1951;59(3):185-93. https://doi.org/10.1086/257075.

Trotter IM, Gomes MFM, Braga MJ, Brochmann B, Lie ON. Optimal LNG (liquefied natural gas) regasification scheduling for import terminals with storage. Energy. 2016;105:80-8. https://doi.org/ 10.1016/j.energy.2015.09.004.

Tsygankova M. An evaluation of alternative scenarios for the Gazprom monopoly of Russian gas exports. Energy Econ. 2012;34(1):153-61. https://doi.org/10.1016/j.eneco.2011.04.009.

Tung C-P, Tseng T-C, Huang A-L, Liu T-M, Hu M-C. Impact of climate change on Taiwanese power market determined using linear complementarity model. Appl Energy. 2013;102(Supplement C):432-9. https://doi.org/10.1016/j.apenergy.2012.07.043.

U-tapao C, Moryadee S, Gabriel SA, Peot C, Ramirez M. A stochastic, two-level optimization model for compressed natural gas infrastructure investments in wastewater management. J Nat Gas Sci Eng. 2016;28(Supplement C):226-40. https://doi.org/10. 1016/j.jngse.2015.11.039.

van Goor H, Scholtens B. Modeling natural gas price volatility: the case of the UK gas market. Energy. 2014;72(Supplement C):126-34. https://doi.org/10.1016/j.energy.2014.05.016.

Venables WN, Smith DM. The R Core Team. An Introduction to R; 2016.

Yan X, Chowdhury NA. Mid-term electricity market clearing price forecasting: a multiple SVM approach. Int J Electric Power Energy Syst. 2014;58(Supplement C):206-14. https://doi.org/10. 1016/j.ijepes.2014.01.023.

Zeng B, Li C. Forecasting the natural gas demand in China using a selfadapting intelligent grey model. Energy. 2016;112(3):810-25. https://doi.org/10.1016/j.energy.2016.06.090.

Zhuang J, Gabriel SA. A complementarity model for solving stochastic natural gas market equilibria. Energy Econ. 2008;30(1):113-47. https://doi.org/10.1016/j.eneco.2006.09.004. 